Revista da Faculdade Mineira de Direito $\mid$ V.21 N.41 $\mid 1$

\title{
O SENTIDO DA PENA E A RACIONALIDADE DE SUA APLICAÇÃO NO ESTADO DEMOCRÁTICO DE DIREITO BRASILEIRO ${ }^{1}$
}

\author{
THE MEANING OF THE PUNISHMENT AND THE \\ RATIONALITY OF ITS APPLICATION AT THE BRAZILIAN \\ DEMOCRATIC STATE
}

Ana Elisa Liberatore S. Bechara²

USP

\begin{abstract}
Resumo
A convergência entre o sentido da pena e a racionalidade de sua aplicação corresponde a um dos temas mais controvertidos do Direito Penal, porque diz respeito à sua própria essência. Nesse contexto, o Direito Penal não pode servir como instrumento político de justificação de um poder arbitrário, e sim como ferramenta crítica fundamental a serviço dos cidadãos e de sua liberdade.

Palavras-chave

Pena. Racionalidade. Estado. Democracia.
\end{abstract}

\begin{abstract}
The intersection between the punishment and the rationality of its application is one of the most difficulties themes of the criminal law, because is the essential point of it. In this context, the criminal law can not be as an arbitrary instrument of the political power, but should be a critical instrument that aims serve the citizens and their liberty.
\end{abstract}

Keywords

Punishment. Rationality. State. Democracy.

\section{Introdução: o papel da dogmática na realidade disfuncional em matéria de penas;}

A convergência entre o sentido da pena e a racionalidade de sua aplicação corresponde a um dos temas mais controvertidos do Direito Penal, porque diz respeito à sua própria essência, sendo, assim, de reflexão

\footnotetext{
${ }^{1}$ Texto correspondente aos apontamentos da aula de erudição ministrada pela autora no concurso público para Professora Titular de Direito Penal da Faculdade de Direito da Universidade de São Paulo aos 15 de setembro de 2017.

${ }^{2}$ Professora Titular da Faculdade de Direito da Universidade de São Paulo
} 
Revista da Faculdade Mineira de Direito | V.21 N.41 $\mid 2$

obrigatória, conforme sintetiza de forma provocadora Tobias BARRETO no início de seu escrito "Algumas ideias sobre o chamado fundamento do direito de punir". ${ }^{3}$ Introduzindo a discussão, afirma em tom crítico e irônico o mestre da Faculdade de Direito do Recife:

"No meio de taes questões sem sahida, parvamente suscitadas, e ainda mais parvamente resolvidas, occupa lugar saliente a celebre questão da origem e fundamento do direito de punir. É uma especie de adivinha, que os mestres crêm-se obrigados a propôr aos discipulos, acabando por ficarem uns e outros no mesmo estado de perfeita ignorancia; o que aliás não impede que os illustrados doutores, na posse das soluções convencionadas, sintamse tão felizes e orgulhosos, como os padres do Egypto a respeito dos seus hieroglyphos".

O trecho citado revela uma constatação perturbadora e bastante atual: apesar do sentido da pena e do conteúdo do delito constituírem os pressupostos metodológicos fundamentais para qualquer desenvolvimento teórico e aplicação do Direito Penal, em pleno século XXI ainda não se tem claro nem um, nem outro conceito, o que revela o Direito Penal como ciência jurídica atormentada ou doente, conforme aponta Gustav RADBRUCH. ${ }^{4}$ Mais ainda, a partir de tais imprecisões, e estando a teoria do delito vinculada à teoria das finalidades da pena, o sistema penal não é capaz de encontrar limites claros relacionados à proteção e respeito ao indivíduo, restando delineado de maneira formal, idealista e, por isso, perigosa em um contexto democrático.

Essa observação preliminar provoca a refletir sobre a legitimidade da pena para além dos universos da dogmática e da lei posta, a fim de buscar seu sentido e racionalidade concretos, no âmbito de uma determinada realidade político-social. E daí surge uma grande dificuldade, já que qualquer reflexão sobre a legitimidade da pena e, assim, do Direito Penal invariavelmente tropeça no questionamento sobre a possibilidade de construir uma racionalidade em relação a uma ciência que está menos

\footnotetext{
${ }^{3}$ BARRETO, Tobias. Menores e loucos e fundamento do direito de punir. Rio de Janeiro: Pongetti, 1926, p. 131. Grafia e itálicos originais do texto.

${ }^{4}$ RADBRUCH, Gustav. Einführung in die Rechtswissenschaft. 11 ${ }^{\mathrm{a}}$ ed. Stuttgart: K.F. Koehler Verlag, 1964, p. 250.
} 
Revista da Faculdade Mineira de Direito | v.21 N.41 $\mid 3$

vinculada ao seu objetivo do que a seus propósitos políticos. Tal dificuldade, aliás, é bem ilustrada na violência e nas contradições que marcam a evolução histórica das penas, que por isso mesmo é tida por Luigi FERRAJOLI como "mais horrenda e infamante para a bumanidade do que a própria bistória dos delitos".

A esse ponto, cabe então uma necessária desmistificação. Tradicionalmente afirma-se que as mudanças históricas pelas quais passaram as práticas punitivas ocorreram de forma evolutiva, no sentido de mudar os hábitos cruéis de execução, tais como o relatado no início da obra de Michael FOUCAULT, ${ }^{6}$ por penas mais civilizadas, humanizando-as. Assim, em 1666, Thomas HOBBES já expunha na obra "Diálogo entre um filósofo e um jurista" a dúvida sobre a legitimidade da pena e a racionalidade de sua aplicação concreta, questionando o jurista a partir da posição do filósofo:

"Quem tem o poder de definir e ordenar o tipo especial de pena para uma infração cometida?" pontua HOBBES, e em seguida afirma: "Uma pena certa nunca pode ser determinada se sua origem está na razão natural dos juízes delegados ou na razão natural do juir supremo. Pois se a lei da razão efetivamente determinasse as penas, então para as mesmas transgressões deveria haver em todo o mundo e em todas as épocas as mesmas penas, porque a lei da razão é imutável e eterna".

Nesse mesmo sentido, em 1764, nas conclusões de seu "Dos delitos e das penas", BECCARIA traduziu claramente a exigência de que "para que não seja violência de um ou de muitos contra um indivíduo particular, a pena deve ser essencialmente pública, necessária, a minima possivel nas circunstâncias dadas, proporcional ao delito e ditada pelas leis". ${ }^{8}$ Dentro do marco do Iluminismo, seria,

${ }^{5}$ FERRAJOLI, Luigi. Derecho y razón. Teoria del garantismo penal. Trad. Perfecto Andrés Ibáñez, A. Ruiz Miguel, J.C. Bayón Mohino, J. Terradillos Basoco, R. Cantarero Bandrés. $5^{\text {a }}$ ed. Madrid: Trotta, 2001, p. 385. Conforme conclui o autor, enquanto o delito constitui normalmente uma violência ocasional e por vezes impulsiva, a violência infligida pela pena é sempre programada, consciente e organizada por muitos contra um. Idem, ibidem.

${ }^{6}$ FOUCAULT, Michael. Vigiar e punir. Trad. Raquel Ramalhete. $26^{a}$ ed. Rio de Janeiro: Vozes, 1987, p. 9-10.

${ }^{7}$ HOBBES, Thomas. Diálogo entre um filósofo e um jurista. Trad. Maria Cristina Guimarães Cupertino. $2^{a}$ ed. São Paulo: Landy, 2004, p. 159.

${ }^{8}$ BECCARIA, Cesare. Tratado de los delitos y de las penas. Traducción de Juan Antonio de las Casas. Madrid: Alianza Editorial, 2002, p. 123. 
Revista da Faculdade Mineira de Direito | v.21 N.41 4

assim, o princípio da humanidade das penas o que melhor distingue, simbolicamente, a ruptura com o terror absolutista, congregando a ideia da pena como limite à intervenção do Estado, incluída aí a garantia de sua previsibilidade ("nulla poena nullum crime sine pravia lege"), o que é coerente com a passagem do homem da condição de súdito para a de cidadão.

Porém, prosseguindo-se na linha evolutiva, observa-se uma concepção de pena que não corresponde propriamente a qualquer evolução em relação ao ideal iluminista. ${ }^{9} \mathrm{Na}$ verdade, muitas vezes ocorre exatamente o contrário. Com efeito, como explicar as concepções positivistas que se sucederam à Escola Clássica no fim do século XIX como uma melhora em matéria de pena? E como entender em sentido evolutivo o estado atual das coisas, em que se verifica de modo crescente o retorno a um caráter aflitivo e cruel das penas, abandonando-se o indivíduo como realidade empírica e base do Direito Penal em prol de um objetivo de estabilização normativa e de resposta simbólica às mais diversas demandas sociais? $\mathrm{Na}$ verdade, verifica-se que a transposição do arbítrio absolutista para uma pretensa racionalidade liberal acabou com o tempo e suas contingências políticas por conceder mais legitimidade simbólica ao Direito Penal, inclusive para a manutenção de um sistema que abandona a crueldade das penas só em seu aspecto formal. Observa-se, assim, que a pena privativa de liberdade não é concretamente mais humana do que as penas corporais que historicamente substituiu, podendo-se afirmar que, longe de uma mera evolução linear, a teoria da pena desenvolve-se sob um movimento pendular característico do Direito Penal em geral, cujo impulso alternado no sentido de maior liberdade ou de maior autoritarismo não é dado pela dogmática, estando na verdade politicamente condicionado.

Afastando-se, então, a afirmação de uma pretensa neutralidade científica na esfera penal, que serve apenas para encobrir uma base ideológica clara, mas não declarada, de justificação, toda a experiência histórica acumulada conduz a um olhar no mínimo desconfiado ao Direito Penal e à teoria da pena, exigindo uma constante reflexão, não obstante suas

\footnotetext{
${ }^{9} \mathrm{Na}$ mesma linha, v. QUEIROZ, Rafael Mafei Rabelo. A modernização do direito penal brasileiro. 'Sursis', livramento condicional e outras reformas do sistema de penas clássico no Brasil, 1924-1940. São Paulo, Quartier Latin, 2007, p. 19.
} 
Revista da Faculdade Mineira de Direito $\mid$ V.21 N.41 $\mid 5$

funções declaradas e suas promessas socialmente tentadoras - e na prática irreais - de eficácia. Em palavras simples, pode-se concluir que a pena é um ato político de violência do Estado.

Pois bem, vistos os pressupostos metodológicos da discussão, há que se retomar a famosa frase contida no Projeto Alternativo do Código Penal Alemão de 1966, segundo a qual "a pena é uma amarga necessidade em uma sociedade de seres imperfeitos como são os homens". Em uma primeira abordagem, poder-se-ia afirmar que tal frase expõe a ideia de que, embora as tendências abolicionistas tenham apontado os problemas do sistema penal que insiste no recurso às sanções tradicionais, não foram e não são capazes de superar tal sistema, por não apresentarem alternativas de resposta, possuindo caráter utópico e eticamente paternalista, conforme aponta Jesús-María SILVA SÁNCHEZ. ${ }^{10}$ Daí a afirmação de Luigi FERRAJOLI de que a alternativa mais adequada ao Direito Penal é ele próprio, mesmo imperfeito, desde que acompanhado de garantias individuais. ${ }^{11}$

Porém, analisando com mais cuidado a frase do Projeto Alternativo do Código Penal Alemão, verifica-se que ela traduz uma aceitação conformada da dogmática em relação à pena, a despeito de suas contradições essenciais insolúveis. O problema de uma interpretação autolegitimada e conformista sobre a pena é que ela gera um raciocínio normativo que distancia as razões jurídicas das razões e consequência sociais do ato estatal de punir, no âmbito do que Cláudio BRANDÃO denomina de "um autismo jurídico que encerra a dogmática em um mundo próprio", ${ }^{12}$ permitindo a manutenção de uma realidade cada vez mais disfuncional e degradante.

E se não há maior questionamento quanto à previsão legal das penas, em sua aplicação concreta as dificuldades avolumam-se, pois as considerações teóricas desempenham um papel ainda mais secundário, cedendo espaço a valorações arbitrárias, estereotipadas e moralmente condicionadas. De fato, a prática judicial pode ser adjetivada de selvagem, sendo impossível concluir que os juízes pensam nas finalidades da pena tal

10 SILVA SÁNCHEZ, Jesús María. Aproximación al derecho penal contemporáneo. Barcelona: José Maria Bosch, 1992, p. 20 e ss.

${ }^{11}$ FERRAJOLI, Luigi. Derecho y razón, cit., p. 342.

12 BRANDÃO, Cláudio. Curso de direito penal. Parte geral. $2^{\mathrm{a}}$ ed. Rio de Janeiro: Forense, 2010, Cap. 1., item 1.3. 
Revista da Faculdade Mineira de Direito | V.21 N.41 6

como as teorias idealistas prescrevem. Tal apagamento dogmático em relação à pena é fruto do que Eugenio Raúl ZAFFARONI denomina de um "raquitismo teórico", 13 que coexiste com uma hipertrofia discursiva no âmbito da teoria do delito, essa cada vez mais refinada e complexa.

Diante de tal quadro, cabe questionar qual o sentido da despreocupação dogmática em relação à pena. Trata-se aparentemente de um paradoxo, já que todo o desenvolvimento sobre a teoria do delito deveria almejar, afinal, chegar ao destino certo da boa aplicação do poder punitivo, correspondente, nos casos de condenação, à aplicação de uma sanção justa.

$\mathrm{Na}$ verdade, em matéria de pena observa-se um fenômeno estarrecedor: sempre se afirma criticamente uma grande desconexão entre dogmática e prática penal, o que retiraria da primeira valor concreto, como instrumento de garantia do cidadão contra o poder de punir do Estado. No caso das penas, de forma totalmente distinta, a dogmática cumpre um papel claro e perverso. Não que haja uma coerência entre as finalidades dogmaticamente atribuídas à pena e sua finalidade concreta; não há tal congruência e não parece haver preocupação sobre isso. O que a dogmática faz, na verdade, é sustentar ou justificar formalmente uma prática judicial arbitrária, na medida em que a camufla, sob um suposto manto de racionalidade, como pretenso marco legítimo para a aplicação das penas.

Exatamente por isso, vive-se hoje uma realidade carcerária intolerável no Brasil, por conta da qual o país já foi, inclusive, condenado no plano internacional. Em números absolutos, o Brasil corresponde ao $4^{\circ}$ país do mundo em número de encarcerados, atrás de EUA, China e Rússia - mas talvez se já tenha superado a Rússia, haja vista que o último Levantamento Nacional de Informações Penitenciárias data de 2014, o que revela o descaso brasileiro com o tema. ${ }^{14} \mathrm{~A}$ taxa brasileira de aprisionamento supera 300 pessoas para cada 100 mil habitantes e segue crescendo em média 7\% ao ano. A taxa de ocupação do cárcere é de $167 \%$, com as piores

${ }^{13}$ ZAFFARONI, Eugenio Raúl; ALAGIA, Alejandro; SLOKAR, Alejandro. Derecho penal. Parte general. $2^{\mathrm{a}}$ ed. (reimpr.). Buenos Aires: Ediar, 2008, p. 993.

${ }^{14}$ N.A. posterior à aula originalmente ministrada: Atualmente o Brasil já assumiu a terceira posição mundial em número de encarcerados. 
Revista da Faculdade Mineira de Direito | V.21 N.41 $\mid 7$

condições possíveis, sendo que 61,6\% dos presos são negros e apenas $13 \%$ participavam em 2014 de alguma atividade educativa.

Essas estatísticas não representam disfuncionalidades do sistema, como teimam em afirmar alguns dogmatas do Direito. Esse é o sistema. Em outras palavras: a culpa não é das estrelas, do orçamento, da crise econômica, do subdesenvolvimento do Estado, como também adverte David GARLAND. ${ }^{15}$ A culpa é do próprio Direito, que trata de estabilizar e justificar uma realidade deliberadamente arbitrária, cruel e desumana. E como é possível tal estabilização de um denominado "estado de coisas inconstitucional", ${ }^{16}$ no âmbito de uma sociedade democrática?

Como é possível que a sociedade não se sensibilize com a forma pela que se aplicam as penas e não se dê conta do sofrimento representado pela pena? Tal sofrimento é, aliás, frequentemente exposto à sociedade pela denominada "baixa cultura jurídica", a exemplo de Graciliano RAMOS, em "Memórias do Cárcere", e Lima BARRETO que foi ele mesmo um objeto da intervenção penal, em "Cemitério dos Vivos".

Essa insensibilidade social é reflexo de uma situação de vitimização, no âmbito de um punitivismo que faz com que a sociedade apenas seja capaz de questionar a pena aplicada a um agente quando antevê excepcionalmente sua inocência. A verdadeira questão, porém, está em refletir criticamente sobre as penas impostas a agentes que de fato sejam responsáveis pela prática de delitos, e aí é preciso coragem para defender os direitos individuais desses delinquentes, que não deixam de ser cidadãos. E esse discurso de resistência é sempre difícil no âmbito de uma pósmodernidade em que se trava uma verdadeira guerra contra a ilustração ${ }^{17} \mathrm{e}$ contra o Direito Penal liberal.

${ }^{15}$ GARLAND, David. The culture of control: crime and social order in contemporary society. Chicago: University of Chicago Press, 2001.

${ }^{16}$ Conforme expressão/tese utilizada no âmbito do julgamento da ADPF 347, ajuizada em razão das inúmeras violações de direitos humanos no sistema carcerário brasileiro, perante o Supremo Tribunal Federal. A origem do estado de coisas inconstitucional remonta, porém, à Corte Constitucional da Colômbia, que a empregou pela primeira vez em 1997, também em matéria penitenciária.

${ }_{17}$ Nesse sentido, v. HABERMAS, Jürgen. El discurso filosófico de la modernidad. Trad. Manuel Jiménez Redondo. Madrid: Taurus, 1989, pág. 15. 
Revista da Faculdade Mineira de Direito | V.21 N.41 8

Tendo em vista que o jurista não pode limitar seu compromisso com a sociedade a uma análise das normas, prescindindo de sua aplicação, optamos por uma abordagem concreta do tema, tomando a pena não apenas como instituto abstrato, mas fundamentalmente no momento de sua aplicação, e assim nos dedicaremos a discutir 3 questões: (i) qual o sentido da pena a partir do limite democrático de respeito ao indivíduo e à liberdade; (ii) se o princípio da individualização da pena configura, tal como é hoje aplicado, um limite consistente para limitar a atuação judicial na determinação da pena; e (iii) quais devem ser os critérios para a orientação democrática da aplicação da pena tendo em vista o sujeito.

\section{Desmistificação do discurso tradicional sobre as finalidades da pena e o sentido da pena no contexto democrático brasileiro}

A dogmática penal continental de influência germânica há tempos chegou a um consenso sobre os três elementos que, sozinhos ou combinados entre si, conformam as distintas teorias sobre a finalidade da pena, a saber: a retribuição, a prevenção geral e a prevenção especial. Para que se proceda a uma brevíssima digressão história do discurso jurídico de legitimação da pena, é preciso ver, porém, que toda finalidade se vincula a uma justificação, conforme observa Antonio Luis Chaves CAMARGO. ${ }^{18}$ Então, ao lado das finalidades da pena, há que tratar de seus fundamentos - a culpabilidade e a periculosidade -, os quais se relacionam filosoficamente a distintas ideias de Direito.

Uma primeira ideia de Direito é a de justiça, que em matéria de pena poderia ser compreendida como justiça igualitária, no sentido distributivo. A partir de tal ideia, desenvolvem-se as denominadas teorias retributivas, fundadas no livre-arbítrio e vinculadas a um juízo formal, sem buscar qualquer tipo de argumento utilitário da pena, conforme se verifica a partir do sentido categorial de punição proposto por KANT ou da concepção de reestabelecimento da ordem jurídica perturbada pelo delito, de HEGEL.

${ }^{18}$ CAMARGO, Antonio Luís Chaves. Sistema de penas, dogmática jurídico-penal e política criminal. São Paulo: Cultural Paulista, 2002. 
Revista da Faculdade Mineira de Direito | V.21 N.41 $\mid 9$

Os problemas da adoção dessa ideia de justiça igualitária em relação ao Direito Penal decorrem fundamentalmente de sua incapacidade de prover uma equação que torne mensuráveis as realidades heterogêneas do delito e da pena, ademais de não trazer outros objetivos além da própria repressão ao delito por si mesma. ${ }^{19}$ Por isso, principalmente após a Segunda Guerra Mundial, e a partir da ênfase das Cortes Constitucionais dos Estados edificados com base em Constituições sobre a necessidade de subordinação do poder de punir à demonstração de sua concreta utilidade social, as teorias retributivas passaram a ser em geral desprezadas pela doutrina, a exemplo dos escritos de Ulrich KLUG ${ }^{20}$ e de Claus ROXIN. ${ }^{21}$ É bem verdade que há na atualidade um movimento para a recuperação da concepção retributiva, agora em uma linha limitadora, no sentido ético de só admitir a punição nos casos de estrita ofensa a bens jurídicos essenciais à pessoa, conforme defende Wolfgang NAUCKE. ${ }^{22}$ Esse retorno à retribuição não parece aceitável, diante da exigência de que o Direito Penal deve sempre apresentar alguma contribuição social em contraposição à sua violência. $\mathrm{Na}$ verdade, o único elemento racional a resgatar da retribuição é o princípio regulativo de mínima proporcionalidade da punição, que não deriva propriamente de uma finalidade retributiva, mas sim da necessidade de contenção da irracionalidade do poder.

A segunda ideia de Direito que pode influenciar a determinação da finalidade da pena é a da segurança jurídica, expressão polissêmica que, para aquilo que nos interessa, designa o conjunto de condições que permitem a cada indivíduo confiar que os direitos e deveres que o ordenamento jurídico assegura sejam respeitados. A ideia de segurança jurídica se relaciona, assim,

${ }^{19}$ No mesmo sentido, v. GUZMÁN DÁLBORA, José Luis. La concreción judicial de la penalidad y su relación con el sentido de la punición. Revista de la Fundación Internacional de Ciencias Penales, mar. 2017, p, 4.

${ }^{20}$ KLUG, Ulrich. Abschied von Kant und Hegel. In: BAUMANN, Jürgen (hrsg.). Programme für ein neues Strafgesetz. Frankfurt am Maim: Fischer, 1968.

${ }^{21}$ ROXIN, Claus. Sentidos e limites da pena estatal. In: Problemas fundamentais de direito penal. Trad. Ana Paula dos Santos e Luis Nastscheradetz. Lisboa: Veja, 1998, p. 19.

${ }^{22}$ NAUCKE, Wolfgang. O alcance do direito penal retributivo em Kant. In: GRECO, Luís; TORTIMA, Fernanda (org.). O bem jurídico como limitação do poder estatal de incriminar? Rio de Janeiro: Lúmen Juris, 2011, p. 95 e ss. 
Revista da Faculdade Mineira de Direito | v.21 N.41 10

com um objetivo empírico da pena de prevenção geral dos delitos, típico do individualismo liberal. ${ }^{23}$

Sob a perspectiva da segurança jurídica, tem-se de um lado as teorias da prevenção geral negativa, ou da dissuasão, e, de outro, as teorias de prevenção geral positiva. As teorias de prevenção geral negativa foram construídas sobretudo pelas contribuições de FEUERBACH, ROMAGNOSI e BENTHAM, medindo a pena a partir de uma exemplarização, como esclarece Anibal BRUNO, ${ }^{24}$ cuja legitimidade é bastante questionável, por não oferecer limites ao poder punitivo do Estado e buscar seu fundamento fora do delito e do sujeito concreto. De outro lado, as teorias de prevenção geral positiva buscam reforçar simbolicamente a internalização de valores pela sociedade, seja no sentido de reforço aos valores ético-sociais elementares, conforme defende Hans WELZEL, ${ }^{25}$ seja de proteção da consciência social sobre a norma, conforme Winfried HASSEMER, ${ }^{26}$ seja de reafirmação simbólica do sistema social diante da desnormalização provocada pelo delito, na linha de Günther JAKOBS. ${ }^{27}$

Assim como ocorre com a justiça distributiva, a aplicação da ideia da segurança jurídica na teoria da pena falha em sua missão mais importante, que seria a de oferecer um critério certo para a configuração do sistema penal. Isso porque não se trata na prevenção geral, de igualar a pena à proporção do delito, mas sim de equacioná-la conforme o temor ou a satisfação da sociedade, como se pudesse situá-la como uma estrutura pautada no consenso, o que DURKHEIM já havia negado no final do séc. XIX. As teorias preventivas gerais acabam, assim, utilizando o agente como

23 No mesmo sentido, GUZMÁN DÁLBORA, José Luis. La concreción judicial de la penalidad y su relación con el sentido de la punición, cit., p. 5-6.

${ }^{24}$ BRUNO, Anibal. Direito penal: pena e medida de segurança. Rio de Janeiro: Forense, 1962 , p. 38.

25 WELZEL, Hans. Derecho penal alemán. Parte General. $11^{\mathrm{a}}$.edição. (4ª . edição castellana). Trad. Juan Bustos Ramírez e Sérgio Yáñez Pérez. Santiago de Chile: Editorial Jurídica de Chile, 1993.

${ }^{26}$ HASSEMER, Winfried. Fines de la pena en el derecho penal de orientación científicosocial. In: MIR PUIG, Santiago (ed.). Derecho penal y ciencias sociales. Barcelona: Universidad Autonoma de Barcelona, 1982.

27 Sociedad, norma y persona en una teoría de un derecho penal funcional. Trad. Manuel Cancio Meliá e Bernardo Feijoo Sánchez. Madrid: Cuadernos Civitas, 1996. 
Revista da Faculdade Mineira de Direito $\mid$ v.21 N.41 $\mid 11$

meio para atingir o fim de aplacar ânimos intranquilos ou de promover o conformismo em relação à situação existente.

Finalmente, tem-se a ideia de utilidade do Direito, também denominada de adequação ao fim, relacionada com a pretensão subjetiva de que o Direito, aí incluída a pena, cumpra um objetivo útil à sociedade, ${ }^{28}$ evitando que os delinquentes voltem a cometer delitos. Esse objetivo é influenciado pelo positivismo criminológico, que substitui a culpabilidade pela periculosidade como fundamento da pena.

Sob essa perspectiva, tem-se de um lado a prevenção especial negativa, que visa fundamentalmente à inocuização do condenado, o que corresponde a um dos enunciados do famoso Programa de Marburgo de Franz von LISZT, encontrando sua vertente mais radical na concepção de eliminação orgânica do condenado, de Raffaelle GAROFALO. Em ambos os autores, transparece o ideal de defesa social em desconsideração dos direitos e interesses do condenado, considerado perigoso e, assim, um inimigo social.

As teorias de prevenção especial positiva, por sua vez, são voltadas à ressocialização do condenado, ideal que soa tentador como finalidade da pena, mas que enfrenta vários problemas. O primeiro deles consiste na impossibilidade de exigir do indivíduo no contexto democrático pluralista um ajuste de personalidade e de concepção de mundo conforme a ideologia dominante. O segundo problema é a contradição da busca da ressocialização por meio da pena, já que toda punição supõe um estigma e uma humilhação. Justamente por isso, as teorias "RE" (reeducadoras, ressocializadoras, reintegradoras) assistiram a uma derrocada a partir da década de 1970, quando o trabalho de Robert MARTINSON ("What Works? Questions and answers about prision reform") concluiu que nenhuma das atividades ressocializadoras funcionava, obrigando, inclusive, à conclusão de que a pena jamais pode ser tomada como um bem para quem a sofre. E, no âmbito brasileiro, é interessante notar que Tobias BARRETO, sempre na vanguarda do Direito Penal, já renunciava a seu tempo a trabalhar com o que chamou de "questão ociosa do melhoramento e correção do criminoso por meio

${ }^{28}$ Cf. GUZMÁN DÁLBORA, José Luis. La concreción judicial de la penalidad y su relación con el sentido de la punición, cit., p. 6. 
Revista da Faculdade Mineira de Direito $\mid$ v.21 N.41 $\mid 12$

da pena", convicto de que, em suas próprias palavras: "o Direito não partilha com a escola e com a igreja a difícil tarefa de corrigir e melhorar o homem moral". ${ }^{29}$

O veneno mais importante que a finalidade de prevenção especial inocula, ainda que de forma dissimulada, por meio do slogan pretensamente positivo da ressocialização, é a periculosidade como fundamento da pena, levando a uma "pedagogia penitenciária" arbitrária, baseada na defesa social, e, assim, a um Direito Penal de Autor. E se o fundamento da pena é a periculosidade do sujeito, para o fim de defender a sociedade da prática de novos delitos, já não faz sentido lógico falar de "direitos subjetivos" do condenado durante a execução da pena, mas sim de "benefícios" que o Estado the pode bondosa e excepcionalmente conferir.

Essa imagem da pena em que o sistema absorve o corpo indesejado com a finalidade de posteriormente incluí-lo novamente como parte integrante do sistema social, conforme a ilustração de Massimo PAVARINI ("La penalità, oggi, nella crítica penológica"), é redesenhada no séc. XX, sobretudo na Europa por conta das políticas do Estado Social. Assim, temse por exemplo no art. 25,2 da Constituição espanhola que "as penas são orientadas à reeducação e à reinserção social'. Da mesma forma, na Constituição italiana, o art. 27 estabelece que "as penas devem ser orientadas à reeducação do condenado". O Brasil foi influenciado por essa vertente, ainda que nunca tenha sido propriamente um Estado Social. Assim, a Lei de Execução Penal brasileira prevê a busca da reintegração social do condenado no art. $1^{\circ}$. Da mesma forma, a Convenção Americana sobre Direitos Humanos, vinculante para o Brasil, também estabelece no art. 5.6 "a reforma $e$ a readaptação dos condenados, como finalidade essencial das penas privativas de liberdade".

Se no cenário nacional é difícil aceitar a prevenção especial positiva como como finalidade da pena, no âmbito europeu a justificação da pena com essa finalidade parece atualmente ainda mais complicada e, assim, retórica, na medida em que se observa a presença crescente de imigrantes ilegais, que somam um volumoso contingente nas casas penais (na Itália estimam-se que sejam cerca de $35 \%$ da população carcerária) e que após o término da pena serão provavelmente expulsos. Tudo a evidenciar, como

${ }^{29}$ BARRETO, Tobias. Estudos de direito. (Publicação póstuma dirigida por Sylvio Roméro). Rio de Janeiro: Laemmert, 1892, p. 179. 
Revista da Faculdade Mineira de Direito $\mid$ v.21 N.41 $\mid 13$

faz Sérgio Salomão SHECAIRA, ${ }^{30}$ que no âmbito de uma sociedade cada vez mais globalizada, de forma paradoxal a pena não significa integração, mas medida de exclusão social, por meio da qual os economicamente inúteis são descartáveis, conforme Sygmunt BAUMAN. ${ }^{31}$

Diante das antinomias dos fins da pena, surgem teorias mistas, que mesclam elementos ou momentos das distintas teorias expostas. Em relação a essas teorias, é importante notar criticamente seus riscos, por habilitarem mais facilmente o poder punitivo, soando muito mais como uma tentativa retórica de legitimação da pena a qualquer custo do que uma construção racional, inclusive porque pretendem unir ideias de Direito que, como já visto, apresentam importantes contradições entre si. ${ }^{32}$

A par das concepções tradicionais sobre a pena, há duas outras questões chamam a atenção na atualidade. A primeira delas é a ideia de que a pena possa ter uma finalidade voltada à satisfação da vítima, tal como defende Tatjana HÖRNLE. ${ }^{33}$ Esse tema é especialmente importante para o Brasil, na medida em que há projeto de Código Penal tramitando junto ao Congresso Nacional cuja exposição de motivos contém uma supreendente dedicatória a duas crianças vítimas de delitos violentos. A ideia de que a pena deve atender a vítima é apta a gerar uma transformação radical no significado do próprio Direito Penal, que passaria de instrumento de proteção subsidiária de bens jurídicos a mecanismo destinado à reparação

\footnotetext{
${ }^{30}$ SHECAIRA, Sérgio Salomão. Exclusão moderna e prisão antiga. In: SÁ, Alvino Augusto; TANGERINO, Davi de Paiva Costa; SHECAIRA, Sérgio Salomão. Criminologia no Brasil. Rio de Janeiro: Elsevier, 2011, p. 5-6.

${ }^{31}$ BAUMANN, Sygmunt. Europa. Uma aventura inacabada. Trad. Carlos Alberto Medeiros. Rio de Janeiro: Jorge Zahar, 2006, p. 106.

32 Nesse sentido, interessante a crítica de Eugenio Raúl ZAFFARONI e Nilo BATISTA sobre os riscos das teorias mistas ou unificadoras da pena, em razão de seu caráter autoritário: "As combinações teóricas incoerentes, em matéria de pena, são muito mais autoritárias do que qualquer uma das teorias puras, pois somam as objeçôes de todas as que pretendem combinar e permitem escolher a pior decisão em cada caso." ZAFFARONI, Eugenio Raúl; BATISTA, Nilo; ALAGIA, Alejandro; SLOKAR, Alejandro. Direito penal brasileiro I. Rio de Janeiro: Revan, 2003, p. 140.

33 HÖRNLE, Tatiana. Die Rolle des Opfers in der Straftheorie und im materiellen Strafrecht. JuristenZeitung, 2006, p. 950 e ss. Da mesma autora, v. também Teorías de la pena. Bogotá: Universidad Externado de Colombia, 2015.
} 
Revista da Faculdade Mineira de Direito | V.21 N.41 $\mid 14$

dos direitos das vítimas, com a introdução de conteúdos emocionais no sistema penal, conforme apontam Jesús-María SILVA SÁNCHEZ ${ }^{34}$ e Alicia GIL GIL. ${ }^{35}$ Assim, não parece possível determinar a pena a partir das necessidades da vítima, porque isso conduziria a uma descivilização penal, retomando formas de castigo passionais, retributivas e excessivas.

A outra questão atual a examinar é a finalidade da pena no âmbito do Direito Penal Internacional, no qual nos deparamos com a figura da "pena sem soberano", conforme a expressão de GLESS, utilizada por Kai AMBOS. ${ }^{36}$ Tem-se aqui um Direito Penal não imposto pelo Estado, mas sim por entidades internacionais ou supranacionais, derivado de uma necessidade jurídica e moral de castigo a violações de direitos universais, no sentido de uma retribuição kantiana. Essa finalidade retributiva causa especial preocupação, em razão da cada vez maior influência dos elementos do Direito Penal Internacional nos ordenamentos penais internos dos Estados como fontes de Direito. O risco aqui é que, pela via do Direito Penal Internacional, a finalidade retributiva da pena acabe retornando com força ao Direito Penal.

Terminado o rápido panorama das teorias da pena, é preciso admitir que, na verdade, nenhuma delas consegue explicar de forma coerente a realidade. E parece lamentável que boa parte da dogmática se limite a repetir tais teorias durante quase dois séculos de forma descritiva. Mais lamentável ainda é ver que as teorias da pena, de origem europeia, são importadas e largamente utilizadas no âmbito da América Latina sem que se dê conta da necessidade de uma contextualização espaço-temporal do poder de punir e de suas consequências. No caso brasileiro, como tratar de pena sem levar em consideração a conformação social racista e a própria evolução da dinâmica político-econômica?

\footnotetext{
34 SILVA SÁNCHEZ, Jesús-María. Una crítica a las doctrinas penales de la "lucha contra la impunidad" y del "derecho de la víctima al castigo del autor". Revista de Estudios de la Justicia, n. 11, 2009.

${ }^{35}$ GIL GIL, Alicia. Sobre la satisfacción de la víctima como fin de la pena. InDret n. 4/2016. 36 AMBOS, Kai. ¿Castigo sin soberano? La cuestión del "ius puniendi" en derecho penal internacional. Una primera contribución para una teoría del derecho penal internacional consistente. Persona y Derecho: Revista de fundamentación de las Instituciones Jurídicas y de Derechos Humanos, 2013, p. 5 e ss.
} 
Revista da Faculdade Mineira de Direito $\mid$ v.21 N.41 $\mid 15$

Ora, conforme a teoria materialista da pena da Escola de Frankfurt, todo sistema político-econômico tem uma tendência a descobrir sistemas punitivos que correspondam às próprias relações de produção. Então a história da pena é a história da evolução das estratégias de imposição de uma ordem social pelas classes hegemônicas, conforme lembram Alessandro BARATTA $^{37}$ e, também no contexto italiano, Dario MELOSSI e Massimo PAVARINI. ${ }^{38}$ Essa lógica econômica faz muito sentido no caso brasileiro, a exemplo das penas aplicadas no contexto histórico do escravismo, em que o castigo corporal se prestava a preservar a força de trabalho, enquanto a pena capital era aplicada em face dos atentados contra o senhor e o sistema, em todo caso sempre de acordo com a situação do mercado de escravos, conforme aponta em suas obras Nilo BATISTA. ${ }^{39}$ E essa mesma lógica parece se aplicar ainda hoje. Afinal, como afirma Alessandro DE GIORGI, no sentido atuarial, "mão de obra excessiva, encarceramento galopante". 40

Diante de todo o exposto, parece que se chegou a um beco sem saída em matéria de finalidades da pena. De todo modo, ainda há que tentar responder a primeira pergunta proposta, sobre qual é o sentido da pena no contexto democrático. E aí parece interessante retomar a famosa frase de John PRATT: "O desenvolvimento social dos povos demonstra-se pela forma como reagem frente ao delito e tratam o delinquente". ${ }^{41}$ Em uma sociedade democrática, a resposta ao delito não se viabiliza apenas com a pena, e menos ainda unicamente com a pena privativa de liberdade. Há que buscar respostas integrais a problemas complexos. Por isso, no séc. XXI, diante das muitas velhas e novas questões que perturbam a sociedade, no âmbito democrático

37 BARATTA, Alessandro. Criminología crítica y crítica al derecho penal. Introducción a la sociología jurídico-penal. Trad. Álvaro Bunster. Buenos Aires: Siglo XXI Editores, p. 193 e ss.

38 MELOSSI, Dario; PAVARINI, Massimo. Cárcere e fábrica. As origens do sistema penitenciário (séculos XVI-XIX). Trad. Sérgio Lamarão. Rio de Janeiro: Revan, 2006, p. 209 e ss.

39 BATISTA, Nilo. Pena pública e escravismo. Capitulo Criminológico, v. 34, n. 3, JulioSeptiembre 2006, p. 279 e ss.

${ }^{40}$ DE GIORGI, Alessandro. A miséria governada através do sistema penal. Rio de Janeiro: Revan, 2006, p 15-16, 51.

${ }^{41}$ PRATT, John. Punishment and Civilization: penal tolerance and intolerance in modern sciety. London: Sage, 2002. 
Revista da Faculdade Mineira de Direito | v.21 N.41 16

deve-se flexibilizar não as garantias individuais, mas sim as penas, em seu juízo de necessidade e de prevenção. Assim, a pena somente poderá assumir um sentido preventivo legítimo se essa prevenção não for simbolicamente vinculada à máxima eficácia possível, e sim à mínima prevenção imprescindível. Isso significa um desapego no sentido de punição, isto é, a busca sempre que possível por algo melhor do que o Direito Penal. Significa também tomar a sociedade em sua realidade desigual e, portanto, de dissenso. Significa que as penas devem incidir muito menos, que devem buscar ser distintas da prisão e que às vezes há que deixar de aplicá-las. Claro que isso implica mudar todo o sistema penal, cuja coluna vertebral ainda é a prisão, e abandonar um tabu, o que é fundamental para nos levar a enxergar novamente o Direito Penal não só como instrumento de defesa social, no sentido eficientista, mas antes como instrumento de defesa do indivíduo e de seus direitos fundamentais, a começar pela liberdade. Sob essa perspectiva democrática, passemos, então, a analisar se o princípio da individualização da pena configura, tal como é hoje aplicado no Brasil, um limite consistente para limitar a atuação judicial na determinação da pena.

\section{O princípio da individualização da pena como limite} (in)consistente da atuação judicial: crítica à influência do positivismo criminológico no ordenamento jurídico-penal brasileiro

A individualização da pena, atualmente entendida como decorrência do princípio da humanidade das penas e garantida pela Constituição Federal Brasileira no art. 5, XLVI, implica que a sanção penal não seja completamente predeterminada, permitindo ao juiz alguma discricionariedade para, entre o mínimo e o máximo legalmente previstos, aplicar a cada caso uma solução justa. Nessa linha, a função do juiz revelase uma instância político-criminal essencial, na medida em que encerra a etapa axiologicamente mais importante do sistema penal, que é a materialização da sanção em casos concretos. Porém, o poder legitimamente conferido ao juiz jamais pode confundir-se com arbítrio, conforme lembra Heleno Cláudio FRAGOSO na obra clássica "A motivação da sentença na 
Revista da Faculdade Mineira de Direito $\mid$ v.21 N.41 $\mid 17$

aplicação da pena”, ${ }^{42}$ que conclui que o único mecanismo de controle nesse sentido é a motivação das sentenças, como obra de razão e de persuasão, na linha de Chaim PERELMAN, o que, aliás, é exigido pela própria Constituição brasileira no art. 93. Mas essa exigência de motivação, tão bem trabalhada por Antônio Magalhães GOMES FILHO no âmbito processual, ${ }^{43}$ só cumpre seu objetivo de controle quando há critérios claros sobre o objeto da decisão judicial.

Ora, em matéria de penas, apesar de ter ocorrido a Reforma da Parte Geral de 1984, que pôs fim ao embate metodológico entre Roberto LYRA e Nelson HUNGRIA e estabeleceu, com fundamento a este último autor, o critério trifásico de aplicação da pena, de modo a tornar o processo formalmente mais claro, não existem no Brasil diretrizes legais objetivas e critérios dogmáticos unívocos a orientar sua concreta aplicação. De fato, a abertura valorativa do art. 59 do Código Penal brasileiro o torna um tipo penal perigoso, porque permite o arbítrio judicial. $\mathrm{O}$ maior problema do julgador não está, assim, na identificação concreta das circunstâncias judiciais nos autos, mas na própria necessidade de atribuição de conteúdo ou significado a essas circunstâncias, como passo prévio ao processo valorativo.

Diante dessas dificuldades, na prática se verifica de forma perturbadora que a suposta garantia da individualização da pena acaba se transformando em um instituto que traz enorme prejuízo ao indivíduo, implicando muitas vezes uma punição mais severa e autoritária. Perguntase, então, como é possível que uma garantia individual se transforme num instrumento punitivista?

$\mathrm{Na}$ verdade, não ocorre propriamente essa transmutação, porque a individualização da pena não nasceu no plano teórico como uma garantia individual. Então, para entendermos o sentido da aplicação disfuncional da pena no Brasil atual, é necessário examinarmos a história do sentido da individualização da pena em nosso ordenamento jurídico.

42 FRAGOSO, Heleno Cláudio. A motivação da sentença na aplicação da pena. Revista Forense, Rio de Janeiro, 1969, v. 227.

43 GOMES FILHO, Antônio Magalhães. A motivação das decisões penais. $2^{\mathrm{a}}$ ed. São Paulo: Saraiva, 2013. 
Revista da Faculdade Mineira de Direito $\mid$ v.21 N.41 $\mid 18$

No Código Criminal do Império de 1830, apontado como um dos maiores códigos do mundo a seu tempo em razão de sua clareza e precisão técnica, a aplicação da pena era regulada no art. 33 atendendo a concepção da Escola Clássica, segundo a qual, a partir da ideia de livre-arbítrio, a sanção penal deveria ter caráter certo e estar previamente prevista pelas leis, de forma a proteger o indivíduo contra o arbítrio do Estado. Prevalecia, sob essa perspectiva, a ideia de igualdade formal frente ao Direito.

Com o advento da República, surge o Código Penal de 1890, obra de João Batista Pereira, o qual, muito diferente do que ocorrera com o Código anterior, chegou a ser batizado de "o pior Código de todos os tempos", em razão de suas pretensas falhas técnicas. É curioso ver, porém, que as bases do Código Penal de 1890 eram as mesmas do Código Criminal do Império. Então, na verdade a maior crítica ao Código Penal de 1890 talvez não fosse realmente a má técnica legislativa, mas sim o fato de estar fundado em princípios clássicos, quando na época já ganhavam força no Brasil os postulados positivistas. ${ }^{44}$ Assim, por exemplo, tem-se a crítica de Raimundo Nina RODRIGUES, conforme quem: "A adoção de um código único para toda a república foi um erro grave que atentou grandemente contra os princípios mais elementares da fisiologia bumana". "Também Ataliba NOGUEIRA, Professor de Direito Penal da Faculdade de Direito de São Paulo, em sua obra intitulada Pena sem prisão criticou a influência da escola clássica no Código Penal da época.

De fato, como era possível, diante das demonstrações científicas da antropologia criminal sobre as desigualdades, que a metafísica da Escola Clássica levasse ainda o legislador penal a estabelecer uma igualdade jurídica genérica? Ora, no positivismo surge a concepção do delinquente diferente dos não delinquentes. Os criminosos foram, sob tal perspectiva, divididos em classes, na linha de Enrico FERRI, entre alienados, natos ou instintivos, ocasionais e passionais. A partir dessa concepção, havia então a necessidade de desconstruir o sistema penal comunitarista "à prova dos juízes" de

\footnotetext{
${ }^{44}$ Cf. ALVAREZ, Marcos Cesar. A criminologia no Brasil ou como tratar desigualmente os desiguais. Revista de Ciências Sociais, n. 45, p. 692. No mesmo sentido, QUEIROZ, Rafael Mafei Rabelo. Modernização do direito penal brasileiro, cit., p. 196.

${ }^{45}$ Cf. QUEIROZ, Rafael Mafei Rabelo. A modernização do direito penal brasileiro, cit., p. 197.
} 
Revista da Faculdade Mineira de Direito | V.21 N.41 $\mid 19$

BECCARIA e reconstruí-lo a partir da diferenciação de tratamento do delinquente, considerando-se sua temibilidade, sob uma ótica determinista. Opera-se, nesse momento, a passagem do Direito Penal do fato para um Direito Penal de autor. Essa era a visão dos penalistas brasileiros à época, tais como Astholfo REZENDE, Esmeraldino BANDEIRA e Nelson HUNGRIA.

Por isso, o Projeto de Código Penal de Sá PEREIRA, Evaristo de MORAES e Mário Bulhões PREDEIRA, de 1935, que representou o primeiro esforço para superar o classicismo do Código de 1890, adotou na linha positivista a técnica de classificação dos criminosos como um critério a ser considerado pelo juiz no momento de aplicação da pena, conforme a influência do modelo do Código Penal italiano de 1930 e seu famoso art. 133 que previa os tipos criminológicos de delinquente. Passou-se a ver a preponderância do criminoso sobre o crime e, assim, os critérios de fixação da pena eram fundamentalmente subjetivos, destacando-se a personalidade do criminoso, o perigo social que representa, os motivos da prática do crime e a categoria em que fosse classificado. Embora não tenha chegado a converter-se em lei, diante das contingências políticas que levaram ao Estado Novo, esse Projeto deixou importantes marcas positivistas que persistem até hoje. E exatamente por isso recebeu elogios, tais como o de João Aureliano Corrêa de ARAUJO, professor da Faculdade de Direito do Recife:

"O projeto afasta-se do critério tradicional da Escola Clássica para examinar a ofensa causada à sociedade não somente pela gravidade do crime, mas pela temibilidade do homem delinquente, segundo o exame de suas condições físico- psíquicas, ampliando assim a esfera da defesa social e tornando mais eficientes os meios destinados à repressão e prevenção da criminalidade", ${ }^{46}$

Finalmente, tem-se o Código Penal de 1940, projeto de Nelson HUNGRIA, Vieira BRAGA, Narcélio de QUEIROZ e Roberto LYRA, a partir da revisão do Projeto de Alcântara MACHADO. O Código abraçou a ideia de individualização da pena, nos marcos do positivismo, chegando a

46 ARAÚjO, João Aureliano Corrêa. Projecto do código criminal do Brasil. Recife: Imp. Industrial, 1937, p. 4. 
Revista da Faculdade Mineira de Direito | v.21 N.41 20

abandonar até a classificação dos criminosos em favor de uma sistemática totalmente individualizada pelo juiz. Assim, ao lado do crime, eram compreendidos na individualização da pena critérios subjetivos, para que a sanção fosse perfeitamente medida ao condenado, a partir das ideias de periculosidade e de defesa social como alicerces de legitimação da intervenção penal, tal como afirma Anibal BRUNO em sua Teoria da perigosidade criminal. A incorporação do postulado positivista da desigualdade entre criminosos e não criminosos terminou por institucionalizar um dado que, no Direito Penal clássico era apenas um efeito colateral desconfortável da pena: a seletividade do sistema. E considerando que tratamos de um período em que a memória da desigualdade imposta pela escravidão era muito recente, fica fácil entender a razão pela qual a sociedade brasileira se tornou solo tão fértil para a estabelecimento das concepções positivistas, como aponta Rafael Mafei Rabelo QUEIROZ. ${ }^{47}$

Encontra-se, então, o real sentido da individualização da pena, filha do afã classificatório próprio do positivismo criminológico, como critério generalizador, isento de qualquer associação a fins valorados, conforme, aliás, é o conteúdo da monografia de Raymond SALEILLES, "L’individualisation de la peine", de 1898. Então a individualização positivista não tem nada que ver com a concreção da pena no sentido da exigência de graduá-la valorativamente conforme a gravidade do delito cometido pelo agente, porque não trabalha afinal com indivíduos, mas sim com generalizações naturalistas.

A partir dessa necessária explicação histórica, pode-se entender o porquê da aplicação da individualização da pena atualmente em contradição com o caráter garantista determinado pela Constituição de 1988. De fato, a despeito da Reforma da Parte Geral do Código Penal em 1984, que substituiu expressões contidas no art. 59, ainda se segue um modelo legal positivista nessa matéria, o que, aliás, fica claro a partir do próprio texto da Exposição de Motivos da Lei de Execução Penal, que menciona a importância do exame de personalidade do agente no início do cumprimento da pena como fator determinante do tipo de tratamento penal, vinculando expressamente tal exame a critérios recomendados por

${ }^{47}$ QUEIROZ, Rafael Mafei Rabelo. A modernização do direito penal brasileiro, cit., p. 224. 
Revista da Faculdade Mineira de Direito | v.21 N.41 21

Benigno DI TULLIO, ${ }^{48}$ que foi titular da cadeira de Antropologia Criminal da Universidade de Roma e discípulo de LOMBROSO.

Não é de espantar, então, que na aplicação da pena atualmente os juízes levem em consideração ora uma finalidade penal retributiva, ora uma concepção preventiva especial calcada na defesa social, sem qualquer preocupação com as garantias individuais. $\mathrm{Na}$ análise dos elementos do art. 59 do CP, e a despeito de toda a crítica da criminologia, a periculosidade e o determinismo que a acompanha ainda assombram, então, a determinação da pena, num território de subjetividade judicial intangível. As sentenças são apoiadas em elementos irracionais, morais e preconceituosos, tais como as expressões: "o réu possui personalidade voltada para a criminalidade", "culpabilidade acentuada, grave, desfavorável', além da frequente aplicação de um intolerável bis in idem relacionado à reincidência e aos antecedentes do agente.

Sobre o elemento "personalidade", previsto no art. 59 do Código Penal como critério de aplicação da pena, há um problema insuperável: a ausência de precisão conceitual de um conceito extrajurídico. Desde a perspectiva constitucional, conclui-se que não é legítimo ao julgador ingressar nesta esfera, porque a valoração subjetiva e moral da personalidade do réu converte o Direito Penal de fato em Direito Penal de Autor, como advertem Alvino Augusto de $\mathrm{SÁ}^{49}$ e Maria Palma WOLFF ${ }^{50}$

É importante notar que os problemas de aplicação da pena atingem não só os clientes de sempre do sistema penal - a criminalidade de massa , mas também os chamados criminosos de colarinho branco, ainda que esses muitas vezes consigam ao final não ser atingidos pelo sistema, por conta de outros fatores. Nessa linha, trazendo um exemplo bastante concreto da esfera do Direito Penal Econômico, ao condenar funcionários públicos por crimes contra a Administração Pública, é comum observar nas sentenças judiciais a afirmação de que "o réu praticon ação das mais reprováveis, visto que

48 Tais critérios de Benigno Di TULLIO podem ser encontrados em sua obra Trattato di antropologia criminale. Studio clinico e medico-legale ad uso dei medici, dei giuristi e degli studenti. Roma: Editrice Criminalia, 1945.

${ }^{49}$ SÁ, Alvino Augusto de. Desafios da execução penal frente aos processos de construção da imagem do inimigo. Revista Brasileira de Ciências Criminais , v. 99, 2012, p. 215 e ss.

50 WOLFF, Maria Palma. Antologia de vidas e histórias na prisão: emergência e injunção de controle social. Rio de Janeiro: Lumen Juris, 2005. 
Revista da Faculdade Mineira de Direito | v.21 N.41 22

violou a confiança inerente ao exercício da função pública", como se o fato de ser servidor público já não tivesse orientado a decisão político-criminal do legislador de punir de forma autônoma e mais dura tais condutas justamente em razão dos deveres inerentes à função pública.

Da mesma forma, verifica-se frequentemente em decisões judiciais a majoração da pena-base em razão de manifestações de pensamento e modos de vida do réu que nada têm que ver com o delito cometido, representando um ato de criminalização imprópria, o que presentifica a instrumentalização material da antijuridicidade tão característica do Direito Penal produzido na Escola de Kiel, no qual o princípio da legalidade era flexibilizado em nome dos interesses da política nacional-socialista. ${ }^{51}$

E é importante ver que a individualização da pena na linha positivista não atinge só os critérios para a determinação da pena-base do art. 59 do Código Penal. Há inúmeros outros focos do binômio periculosidade-defesa social no ordenamento penal brasileiro a implicar penas desumanas. Assim, pode-se mencionar a Lei dos Crimes Hediondos, que a partir de 1990 lotou e agravou as condições de vida nas prisões brasileiras, cumprindo um papel reprovável de dar à população a falsa ideia segurança por meio de uma lei extremamente repressiva, como critica Alberto Silva FRANCO. ${ }^{52}$ Da mesma forma, sob aparência de uma sanção disciplinar, a Lei Federal n. 10.792/2003 criou o Regime Disciplinar Diferenciado, inaugurando um regime carcerário desumano para presos considerados perigosos, o que tem levado a quadros psiquiátricos irreversíveis e até mesmo ao suicídio. E embora o Conselho Nacional de Política Criminal e Penitenciária do Ministério da Justiça tenha elaborado parecer em agosto de 2004 que concluiu pela incompatibilidade do RDD com as normas nacionais e internacionais acerca dos direitos humanos, tal regime ainda está vigorando, evidenciando a opção deliberada por um sistema penal perigosamente voltado ao combate simbólico de inimigos sociais.

${ }^{51}$ A mesma advertência é feita por CARVALHO, Salo de. Dosimetria da pena: diretrizes e limites constitucionais (análise de caso. Parecer Operação Lava Jato). Revista Brasileira de Ciências Criminais, v. 122, ago. 2016.

${ }^{52}$ FRANCO, Alberto Silva. Crimes hediondos. $5^{a}$. ed. São Paulo: Revista dos Tribunais, 2005, p. 639 e ss. 
Revista da Faculdade Mineira de Direito $\mid$ v.21 N.41 23

Em relação à execução da pena, aliás, principalmente no caso da privativa de liberdade, o descompasso entre os universos do ser e do dever ser se revela ainda mais gritante. Nessa esfera o pretenso ideal de ressocialização não é em geral nem um pouco promovido pelo Estado, e na prática o que era para ser um direito do condenado se transforma em um dever, ou seja, o argumento da ressocialização é usado no momento da avaliação dos direitos subjetivos do condenado como um impeditivo para a conquista da liberdade, como bem defendeu Luis Carlos VALOIS na obra Execução penal e ressocialização. É a famosa frase, vista em tantas sentenças judiciais: " $O$ condenado não se apresenta suficientemente ressocializado para fazer jus ao 'benefício' pleiteado."

Finalmente, encontram-se problemas de individualização em relação às penas alternativas, que são pouco e mal aplicadas, a despeito da Lei 9.714/98 as ter em tese ampliado, lei essa que foi objeto de importante crítica por Miguel REALE JÚNIOR ${ }^{53}$ em razão de ferir toda a sistemática na matéria. E o pretexto é a inviabilidade de sua utilização para a repressão e prevenção em relação a delinquentes que são considerados de forma determinista e indistinta como perigosos. $\mathrm{Na}$ verdade, dado seu desvirtuamento de sentido, com a erosão de seu caráter ressocializador, as penas restritivas de direito são vistas em nosso sistema, então, como alternativas à liberdade, e não alternativas à privação de liberdade, representando uma extensão da rede de controle e punição do Estado.

Então, respondendo à segunda pergunta proposta, sobre se o princípio da individualização da pena configura, tal como é hoje aplicado, um limite consistente para limitar a atuação judicial na determinação da pena, pode-se concluir que não. A aplicação da pena tem como objetivo castigar e é absorvida pela ideia de periculosidade, que invade o terreno da culpabilidade como uma questão de verdade moral. Ocorre aqui, como apontou Nelson HUNGRIA em seus Comentários ao Código Penal, uma conciliação póstuma entre CARRARA e FERRI, isto é, uma vinculação pragmática entre a escola clássica e o positivismo, que é inconciliável do

\footnotetext{
${ }^{53}$ REALE JÚNIOR, Miguel. Mens legis insana, corpo estranho. In: Penas restritivas de direitos. Críticas e comentários às penas alternativas. Lei 9.714/98. São Paulo: Revista dos Tribunais, 1999, p. 23.
} 
Revista da Faculdade Mineira de Direito $\mid$ v.21 N.41 24

ponto de vista metodológico, gerando problemas graves. A individualização da pena nesses moldes, além de afrontar o modelo de Direito Penal do fato, opõe-se a dois dos fundamentos mais importantes do Estado Democrático de Direito: a dignidade humana e o pluralismo político, porque a punição, além de ser aplicada como castigo, é medida a partir de personalidades tidas de forma determinista como divergentes daquelas ditadas como "corretas" pelos detentores do poder, tal qual sintetiza Juan BUSTOS RAMÍREZ. ${ }^{54}$ Em suma, a individualização da pena no Brasil hoje não individualiza, mas massifica os condenados.

\section{Por uma leitura democrática do princípio de individualização da pena: critérios para uma aplicação da pena mais racional}

Diante de todo o exposto, parece necessário tentar mover o pêndulo do Direito Penal para o outro lado, buscando uma maior proteção do indivíduo em face do poder punitivo do Estado em matéria das penas. Para isso, deve-se em primeiro lugar abandonar a ideia de periculosidade e voltar a medir a culpabilidade a partir da ideia de proporcionalidade sobre a qual já tratava BECCARIA. Essa, aliás, é a linha da concepção neoclássica da pena proporcional ao fato, que se centra nas características do delito e contesta a ideia de que a pena possa ser medida em função de prognoses futuras ou critérios morais, tal como defendido por Andrew von HIRSCH em "Censurar y castigar" e por Tajana HÖRNLE em "Determinación de la pena y culpabilidade”. Assim, deve-se ler o art. 59, do Código Penal à luz do art. $3^{\circ}$ da CF, para entender a expressão “repressão" como exigência de que a pena se oriente em função de critérios de proporcionalidade, e não de retribuição, como aponta Juarez TAVARES. ${ }^{55}$

Há que se entender, porém, o sentido que essa proporcionalidade deve assumir num Estado Democrático de Direito. Em primeiro lugar, é importante deixar claro que não se trata de uma proporcionalidade material, mas sim de uma proporcionalidade jurídica. Assim, a proporcionalidade não

${ }^{54}$ BUSTOS RAMÍREZ, Juan. Los mitos de la ciencia penal del siglo XX: La culpabilidad y la perigosidad. In: DÍEZ RIPOLLÉS, José Luís (coord.). La ciencia del derecho penal ante el nuevo siglo: libro homenaje al profesor doctor don José Cerezo Mir. Madrid: Tecnos, 2002, p. 3 e ss.

55 TAVARES, Juarez. Parecer sobre a situação concreta do funcionamento do sistema prisional brasileiro, exarado aos 07 de abril de 2015, p. 12. 
Revista da Faculdade Mineira de Direito | v.21 N.41 25

representa um fim do Direito Penal, mas unicamente a base para que seja possível o alcance de suas finalidades. Em segundo lugar, a análise da proporcionalidade em matéria penal jamais pode deixar de ter em conta os limites impostos a poder de punir do Estado. A partir dessas observações, podemos, então, afirmar a proporcionalidade democraticamente apenas como um limite da pena, e não como seu fundamento.

Se isso é assim, trata-se de manejar a prevenção, como finalidade da pena, fundamentalmente em benefício do agente. Para isso, em primeiro lugar há que se deixar claro que a culpabilidade é a culpabilidade do fato, e não do autor, e que ela deve assumir um caráter negativo ou limitativo, no sentido de constituir uma barreira de proteção do indivíduo contra o Estado com o fim de evitar sua instrumentalização em prol de interesses preventivos. O juízo de culpabilidade deverá corresponder, portanto, ao desvalor da ação e do resultado, relacionando-se à gravidade do fato no sentido de ofensa ao bem jurídico tutelado, e não a juízos hipotéticos fundados na parcialidade ideológica do juiz, conforme defende Juarez TAVARES. ${ }^{56}$ Nessa linha, apenas será democraticamente válida a análise de circunstâncias judiciais que tenham relação com a conduta típica imputada, ou seja, aquelas que, de alguma forma, direta ou indiretamente, influenciaram o sujeito na dinâmica da sua conduta.

Então, não faz sentido a manutenção das circunstancias judiciais subjetivas, relacionadas à vida do indivíduo, o que, aliás, já se apontara em uma proposta de reforma da Parte Geral do Código Penal elaborada em pareceria pelo IBCCRIM e pelo Instituto Carioca de Criminologia em 2000. Isso não significa, porém, deixar de levar em conta os elementos subjetivos do agente para a concreção da pena, mas sim a necessidade de usá-los exclusivamente no sentido funcional de diminuir a sanção penal, tal como afirmam HORN, GIMBERNAT ORDEIG, ZAFFARONI e Juarez TAVARES, inclusive para o fim de buscar alternativas menos dessocializantes. Isso significa, então, que a pena, em um Estado Democrático de Direito, pode ser aplicada aquém do mínimo legal e até

\footnotetext{
56 TAVARES, Juarez. Culpabilidade e individualização da pena. In: Cem anos de reprovação. Uma contribuição transdisciplinar para a crise da culpabilidade. Rio de Janeiro: Revan, 2011.
} 
Revista da Faculdade Mineira de Direito | v.21 N.41 26

mesmo deixar de ser aplicada, a partir da consideração de sua desnecessidade conforme as circunstâncias do caso concreto, em uma visão extensiva do perdão judicial, como sugerem Claus ROXIN em "Prevención y determinación de la pena" e, no Brasil, Marcelo SEMER, em "Princípios penais no estado democrático".

Finalmente, a fim de reorientar democraticamente o princípio da individualização das penas, haveria que se proceder a toda uma reconstrução do sistema de penas, abandonando a pena privativa de liberdade como sanção penal por excelência, em razão de todos os problemas já conhecidos e bem apontados por Ivette Senise FERREIRA, ${ }^{57}$ e conferindo autonomia e prevalência às outras penas. Em suma, respondendo à derradeira pergunta proposta, afirma-se que é possível o aproveitamento da individualização das penas sob a perspectiva democrática, desde que a concreção da sanção penal tome como referência a proteção do indivíduo, e não ideais de retribuição ou de prevenção geral fundadas num modelo moral, orgânico e irreal de consenso social. Individualizar no plano democrático consiste em levar em conta as diferenças.

\section{Conclusões}

Há que se reconhecer, de qualquer forma, o paradoxo de tentar chegar a penas justas dentro de uma sociedade injusta. Isto é, que as penas sejam abstratamente equânimes aos olhos técnicos e acadêmicos não impede que estejam imersas em uma sociedade que mantém sérios vícios de injustiça e que não consegue erradica-los, a começar da pobreza. Portanto, apesar dos esforços científicos que se possam empreender, a pena não será justa sem que se tenha uma sociedade também justa.

Também é verdade que a situação penal em geral no Brasil não é produto exclusivo da forma positivista como ainda se concretizam as sanções penais, sendo de se apontar nesse cenário diversos outros fatores para além da hipótese judicial, tais como o próprio processo de criminalização primária, a dinâmica político-econômica, a conformação social, dentre tantos outros que devem ser estudados tendo em vista nossas

${ }^{57}$ FERREIRA, Ivette. Penas alternativas e substitutivos penais. Consulex, v. 12, n. 3, jan. 1998. 
Revista da Faculdade Mineira de Direito $\mid$ v.21 N.41 $\mid 27$

especificidades como sociedade e Estado. Mas justamente em razão da presença desses outros fatores, o Direito Penal não pode servir como instrumento político de justificação de um poder arbitrário, e sim como ferramenta crítica fundamental a serviço dos cidadãos e de sua liberdade.

Se começamos a exposição com um sergipano, Tobias Barreto, que está vinculado eternamente ao Largo São Francisco por meio de seu verso que constitui a mais bonita de suas trovas acadêmicas, terminaremos com a citação de um baiano, um dos maiores representantes do Brasil e sempre paraninfo dos formandos das Arcadas: Rui BARBOSA. Emprestando, então, uma passagem da Oração aos Moços, diríamos que uma aula não pode ser um simples externar de conhecimentos e autores acumulados, mas uma reflexão crítica, a partir deles, com o fim de contribuir com o progresso do conhecimento científico. Sem a crítica e a ideologia, o professor deixa de ser professor para converter-se em mero transmissor de conhecimento alheio. Espera-se, com as reflexões aqui feitas, ter podido contribuir de algum modo, não com a busca ou a revelação de verdades absolutas, mas sim com um debate sempre aberto para o alcance de um Direito mais justo.

\section{Referências}

ALVAREZ, Marcos Cesar. A criminologia no Brasil ou como tratar desigualmente os desiguais. Revista de Ciências Sociais, n. 45.

AMBOS, Kai. ¿Castigo sin soberano? La cuestión del "ius puniendi” en derecho penal internacional. Una primera contribución para una teoría del derecho penal internacional consistente. Persona y Derecho: Revista de fundamentación de las Instituciones Jurídicas y de Derechos Humanos, 2013.

ARAÚJO, João Aureliano Corrêa. Projecto do código criminal do Brasil. Recife: Imp. Industrial, 1937, p. 4.

BARATTA, Alessandro. Criminología crítica y crítica al derecho penal. Introducción a la sociología jurídico-penal. Trad. Álvaro Bunster. Buenos Aires: Siglo XXI Editores.

BARRETO, Tobias. Estudos de direito. (Publicação póstuma dirigida por Sylvio Roméro). Rio de Janeiro: Laemmert, 1892.

BARRETO, Tobias. Menores e loucos e fundamento do direito de punir. Rio de Janeiro: Pongetti, 1926, 
Revista da Faculdade Mineira de Direito $\mid$ v.21 N.41 28

BATISTA, Nilo. Pena pública e escravismo. Capitulo Criminológico, v. 34, n. 3, Julio-Septiembre 2006.

BAUMANN, Sygmunt. Europa. Uma aventura inacabada. Trad. Carlos Alberto Medeiros. Rio de Janeiro: Jorge Zahar, 2006.

BECCARIA, Cesare. Tratado de los delitos y de las penas. Traducción de Juan Antonio de las Casas. Madrid: Alianza Editorial, 2002,

BRANDÃO, Cláudio. Curso de direito penal. Parte geral. $2^{a}$ ed. Rio de Janeiro: Forense, 2010,

BRUNO, Anibal. Direito penal: pena e medida de segurança. Rio de Janeiro:

Forense, 1962.

BUSTOS RAMÍREZ, Juan. Los mitos de la ciencia penal del siglo XX: La culpabilidad y la perigosidad. In: DÍEZ RIPOLLÉS, José Luís (coord.). La ciencia del derecho penal ante el nuevo siglo: libro homenaje al profesor doctor don José Cerezo Mir. Madrid: Tecnos, 2002.

CAMARGO, Antonio Luís Chaves. Sistema de penas, dogmática jurídico-penal e política criminal. São Paulo: Cultural Paulista, 2002.

CARVALHO, Salo de. Dosimetria da pena: diretrizes e limites constitucionais (análise de caso. Parecer Operação Lava Jato). Revista Brasileira de Ciências Criminais, v. 122, ago. 2016.

DE GIORGI, Alessandro. A miséria governada através do sistema penal. Rio de Janeiro: Revan, 2006.

DI TULLIO, Benigno. Trattato di antropologia criminale. Studio clinico e medico-legale ad uso dei medici, dei giuristi e degli studenti. Roma: Editrice Criminalia, 1945.

FERRAJOLI, Luigi. Derecho y razón. Teoria del garantismo penal. Trad. Perfecto Andrés Ibáñez, A. Ruiz Miguel, J.C. Bayón Mohino, J. Terradillos Basoco, R. Cantarero Bandrés. $5^{\text {a }}$ ed. Madrid: Trotta, 2001, FERREIRA, Ivette. Penas alternativas e substitutivos penais. Consulex, v. 12, n. 3, jan. 1998.

FOUCAULT, Michael. Vigiar e punir. Trad. Raquel Ramalhete. 26 ed. Rio de Janeiro: Vozes, 1987,

FRAGOSO, Heleno Cláudio. A motivação da sentença na aplicação da pena. Revista Forense, Rio de Janeiro, 1969, v. 227.

FRANCO, Alberto Silva. Crimes hediondos. 5a. ed. São Paulo: Revista dos Tribunais, 2005. 
Revista da Faculdade Mineira de Direito | v.21 N.41 29

GARLAND, David. The culture of control: crime and social order in contemporary society. Chicago: University of Chicago Press, 2001.

GIL GIL, Alicia. Sobre la satisfacción de la víctima como fin de la pena. InDret n. 4/2016.

GOMES FILHO, Antônio Magalhães. A motivação das decisões penais. $2^{\mathrm{a}} \mathrm{ed}$. São Paulo: Saraiva, 2013.

GUZMÁN DÁLBORA, José Luis. La concreción judicial de la penalidad y su relación con el sentido de la punición. Revista de la Fundación Internacional de Ciencias Penales, mar. 2017.

HABERMAS, Jürgen. El discurso filosófico de la modernidad. Trad. Manuel Jiménez Redondo. Madrid: Taurus, 1989.

HASSEMER, Winfried. Fines de la pena en el derecho penal de orientación científico-social. In: MIR PUIG, Santiago (ed.). Derecho penaly ciencias sociales. Barcelona: Universidad Autonoma de Barcelona, 1982.

HOBBES, Thomas. Diálogo entre um filósofo e um jurista. Trad. Maria Cristina Guimarães Cupertino. 2a ed. São Paulo: Landy, 2004,

HÖRNLE, Tatiana. Die Rolle des Opfers in der Straftheorie und im materiellen Strafrecht. Juristen Zeitung, 2006, HÖRNLE, Tatiana. Teorías de la pena. Bogotá: Universidad Externado de Colombia, 2015.

JAKOBS, Gunter. Sociedad, norma y persona en una teoría de un derecho penal funcional. Trad. Manuel Cancio Meliá e Bernardo Feijoo Sánchez. Madrid: Cuadernos Civitas, 1996.

KLUG, Ulrich. Abschied von Kant und Hegel. In: BAUMANN, Jürgen (hrsg.). Programme für ein neues Strafgesetz. Frankfurt am Maim: Fischer, 1968.

MELOSSI, Dario; PAVARINI, Massimo. Cárcere e fábrica. As origens do sistema penitenciário (séculos XVI-XIX). Trad. Sérgio Lamarão. Rio de Janeiro: Revan, 2006.

NAUCKE, Wolfgang. O alcance do direito penal retributivo em Kant. In: GRECO, Luís; TORTIMA, Fernanda (org.). O bem jurídico como limitação do poder estatal de incriminar? Rio de Janeiro: Lúmen Juris, 2011.

PRATT, John. Punishment and Civilization: penal tolerance and intolerance in modern sciety. London: Sage, 2002. 
Revista da Faculdade Mineira de Direito | V.21 N.41 30

QUEIROZ, Rafael Mafei Rabelo. A modernização do direito penal brasileiro. Sursis', livramento condicional e outras reformas do sistema de penas clássico no Brasil, 1924-1940. São Paulo, Quartier Latin, 2007.

RADBRUCH, Gustav. Einführung in die Rechtswissenschaft. $11^{\mathrm{a}}$ ed. Stuttgart: K.F. Koehler Verlag, 1964,

REALE JÚNIOR, Miguel. Mens legis insana, corpo estranho. In: Penas restritivas de direitos. Críticas e comentários às penas alternativas. Lei 9.714/98. São Paulo: Revista dos Tribunais, 1999.

ROXIN, Claus. Sentidos e limites da pena estatal. In: Problemas fundamentais de direito penal. Trad. Ana Paula dos Santos e Luis Nastscheradetz. Lisboa: Veja, 1998,

SÁ, Alvino Augusto de . Desafios da execução penal frente aos processos de construção da imagem do inimigo. Revista Brasileira de Ciências Criminais , v. 99, 2012, p. 215 e ss.

SHECAIRA, Sérgio Salomão. Exclusão moderna e prisão antiga. In: SÁ, Alvino Augusto; TANGERINO, Davi de Paiva Costa; SHECAIRA, Sérgio Salomão. Criminologia no Brasil. Rio de Janeiro: Elsevier, 2011, p. 5-6.

SILVA SÁNCHEZ, Jesús María. Aproximación al derecho penal contemporáneo. Barcelona: José Maria Bosch, 1992.

SILVA SÁNCHEZ, Jesús-María. Una crítica a las doctrinas penales de la "lucha contra la impunidad" y del "derecho de la víctima al castigo del autor". Revista de Estudios de la Justicia, n. 11, 2009.

TAVARES, Juarez. Culpabilidade e individualização da pena. In: Cem anos de reprovação. Uma contribuição transdisciplinar para a crise da culpabilidade. Rio de Janeiro: Revan, 2011.

TAVARES, Juarez. Parecer sobre a situação concreta do funcionamento do sistema prisional brasileiro, exarado aos 07 de abril de 2015.

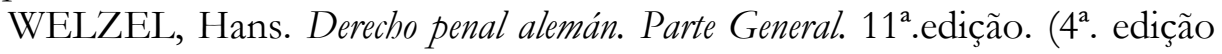
castellana). Trad. Juan Bustos Ramírez e Sérgio Yáñez Pérez. Santiago de Chile: Editorial Jurídica de Chile, 1993.

WOLFF, Maria Palma. Antologia de vidas e histórias na prisão: emergência e injunção de controle social. Rio de Janeiro: Lumen Juris, 2005.

ZAFFARONI, Eugenio Raúl; ALAGIA, Alejandro; SLOKAR, Alejandro. Derecho penal. Parte general. $2^{\mathrm{a}}$ ed. (reimpr.). Buenos Aires: Ediar, 2008, 
Revista da Faculdade Mineira de Direito $\mid$ v.21 N.41 $\mid 31$

ZAFFARONI, Eugenio Raúl; BATISTA, Nilo; ALAGIA, Alejandro; SLOKAR, Alejandro. Direito penal brasileiro I. Rio de Janeiro: Revan, 2003. 